\title{
The Sterol Requirement of Phytophthora cactorum
}

\author{
By C. G. ELLIOTT, MARGARET R. HENDRIE, \\ Botany Department, University of Glasgow \\ AND B. A. KNIGHTS \\ Chemistry Department, University of Glasgow
}

(Received 7 October 1965)

\begin{abstract}
SUMMARY
Several sterols and related substances were tested for ability to promote sexual reproduction in Phytophthora cactorum. These compounds were classified as active (oospores formed), partially active (oogonia and antheridia formed, but no oospores), or inactive (no oogonia). Quantitative differences between active substances were noted in respect of the numbers of oospores produced and the time of their appearance. The most active substances tested were 29 -isofucosterol and $\beta$-sitosterol. Loss of activity was associated with shortening of the side chain of the sterol molecule or change in its configuration, absence of a double bond in the $\mathbf{B}$ ring or of a hydroxyl group at position 3 on the $\mathbf{A}$ ring.
\end{abstract}

\section{INTRODUCTION}

In media which lack sterols the growth of species of the fungal genera Pythium and Phytophthora tends to be purely vegetative. However, in media to which certain sterols are added, vegetative growth is increased and, more significantly, sexual organs (oogonia and antheridia) develop and oospores are formed (Haskins, Tulloch \& Micetich, 1964; Hendrix, 1964, 1965; Elliott, Hendrie, Knights \& Parker, 1964; Leal, Friend \& Holliday, 1964; Harnish, Berg \& Lilly, 1964). In this paper we consider what structural features of the sterol molecule are necessary to confer this physiological activity on it in the case of Phytophthora cactorum (Leb. \& Cohn) Schroet.

\section{METHODS}

Fungus. The strain of Phytophthora cactorum used was IMI 21168, obtained from the Commonwealth Mycological Institute, Kew.

Media. The basal medium had the following composition: sucrose, $10 \cdot 0 \mathrm{~g}$; L-asparagine, 1.0 g.; $\mathrm{KH}_{2} \mathrm{PO}_{4}, 0.5 \mathrm{~g}$.; $\mathrm{MgSO}_{4} .7 \mathrm{H}_{2} \mathrm{O}, 0 \cdot 25$ g.; trace element solution, $1.0 \mathrm{ml}$; thiamine hydrochloride, 1.0 mg.; Difco Bacto-Agar, 10.0 g.; water, 1.0 l. The trace element solution contained: $\mathrm{Na}_{2} \mathrm{~B}_{4} \mathrm{O}_{7} .10 \mathrm{H}_{2} \mathrm{O}, 88 \mathrm{mg}$.; $\mathrm{CuSO}_{4} .5 \mathrm{H}_{2} \mathrm{O}$, $393 \mathrm{mg}$.; $\mathrm{Fe}_{2}\left(\mathrm{SO}_{4}\right)_{3} \cdot 6 \mathrm{H}_{2} \mathrm{O}, 910 \mathrm{mg}$.; $\mathrm{MnCl}_{2} \cdot 4 \mathrm{H}_{2} \mathrm{O}, 72 \mathrm{mg}$.; $\mathrm{Na}_{2} \mathrm{MoO}_{4} \cdot 2 \mathrm{H}_{2} \mathrm{O}, 50 \mathrm{mg}$.; $\mathrm{ZnSO}_{4} .7 \mathrm{H}_{2} \mathrm{O}, 4403 \mathrm{mg}$.; EDTA, 5 g.; water $1 \mathrm{l}$.

Sterols and other substances to be tested were dissolved in diethyl ether and added to the medium after autoclaving and while it was still warm. The concentration of sterol was such that as a rule $1 \mathrm{ml}$. of ether solution was added to each 20 or $25 \mathrm{ml}$. of medium to give the desired final concentration. Pure ether was added to the basal medium as a control. 
Except where otherwise stated the substance under test was added to the medium at the rate of $10 \mathrm{mg} . / \mathrm{l}$.

Culture methods. Small Petri dishes $(5 \mathrm{~cm}$. diameter), each containing $5 \mathrm{ml}$. medium, were used in general; measurements of linear growth rate were made in $9 \mathrm{~cm}$. Petri dishes containing $16 \mathrm{ml}$. medium. The inoculum was a plug of agar $4 \mathrm{~mm}$. diameter cut from a colony growing on the basal medium. For dry weight measurements the fungus was grown in $25 \mathrm{ml}$. liquid medium in $100 \mathrm{ml}$. conical flasks. Incubation was at $25^{\circ}$ in the dark.

Linear growth rate was determined by measuring the diameter of the growing colonies at intervals and calculating regression coefficients by the usual least squares method.

Oospore counts. The number of oospores was counted in a radial transect, the width of a low-power microscope field, from the central inoculum plug to the edge of the dish. Two or three transects were counted in each of several dishes. For the analysis of variance the count per transect, $x$, was transformed to $\left(x+\frac{1}{2}\right)^{\frac{1}{2}}$.

To provide a basis for comparison between experiments, tests on both basal medium and cholesterol were always included.

Chemicals. In the following list, * indicates that the sample was pure according to gas-liquid chromatography (GLC). $\beta$-Sitosterol was extracted from oat seed, and was $90 \%$ pure by GLC, the $10 \%$ impurities being mainly campesterol and cholesterol (Knights, 1965). A mixture of the acetates of isofucosterol and $\Delta^{\mathbf{7 2 4 ( 2 8 )} \text {. }}$ stigmastadienol was also obtained from an extract of oat seed. From this, isofucosterol, sample 1, was prepared, and this contained $10 \%$ stigmasterol (Knights, 1965) according to GLC. Isofucosterol, sample 2, was synthetic material obtained from Dr J. Dusza.

Ergosterol, sample 1, was obtained from Mr D. J. Austin (University of Glasgow), and was about $80 \%$ pure by GLC; sample 2 was obtained from British Drug Houses Limited, and purified by recrystallization from acetone. Fucosterol* was supplied by Dr G. Wood (Organon Limited, Newhouse, Lanarkshire), stigmasteryl acetate* by Professor D. H. R. Barton (Imperial College, London), ergosterol peroxide by Mr I. M. Campbell (University of Glasgow) and 24-dihydrolanosterol by Mr D. J. Austin. Dr C. J. W. Brooks (University of Glasgow) supplied $\Delta^{7}$ cholestenol*, $\Delta^{5}$-cholesten-3-one ${ }^{*}, \Delta^{4,6}$-cholestadien-3-one*, $\Delta^{4}$-cholesten-3-one*, desmosterol*, and a mixture of $\beta$-sitosterol and campesterol (3:1); 7-dehydrocholesterol was obtained from Sigma Chemical Co., and recrystallized from acetone*. $\Delta^{5}$-cholenol* was synthesized from commercial cholenic acid.

\section{RESULTS}

The substances tested are listed in Table 1 , in which they are classified as active, partially active and inactive. The addition of some substances to the medium resulted in the production of oogonia and antheridia followed two days or so later by oospores; these are called active. With other substances oogonia and antheridia were produced but no oospores were formed, and generally the contents of the oogonia degenerated after about 4 days; these substances are called partially active. With inactive substances no oogonia or antheridia were produced, or exceptionally a few appeared at a late stage of growth and then at the same time in both supplemented and basal medium. 


\section{Active substances}

In addition to the substances shown in the first part of Table 1 mixtures of $\beta$-sitosterol and campesterol $(3: 1)$ and of the acetates of 29 -isofucosterol $\left(\Delta^{5,24(28)}\right.$ stigmastadienol) and $\Delta^{7,24(28)}$-stigmastadienol $(2: 1)$ were active.

The effects of varying concentrations of $\beta$-sitosterol and cholesterol on vegetative growth and on oospore production were examined and are shown for $\beta$-sitosterol in Figs. 1, 2 and Table 4, Expt. 4. At high concentrations the hyphal growth rate was decreased but the dry weight of organism was relatively little affected; the colony was correspondingly denser. Hendrix (1965) also found increased vegetative growth in cholesterol medium.

Table 1. List of substances tested and summary of results

\begin{tabular}{|c|c|}
\hline Active & Partially active \\
\hline $\begin{array}{c}\text { (oogonia, antheridia and } \\
\text { later oospores) }\end{array}$ & (oogonia and antheridia only) \\
\hline Cholesterol & Cholestanol \\
\hline Cholesteryl acetate & Epicholestanol \\
\hline$\beta$-Sitosterol & $\Delta^{\frac{1}{5}}$-Cholenol \\
\hline$\beta$-Sitosteryl acetate & $\Delta^{5}$-Cholesten-3-one \\
\hline 29-Isofucosterol & $\Delta^{4}$-Cholesten-3-one \\
\hline Stigmasteryl acetate & $\Delta^{4,6}$-Cholestadien-3-one \\
\hline Ergosterol & \\
\hline Fucosterol & \\
\hline$\Delta^{7}$-Cholestenol & \\
\hline \multicolumn{2}{|c|}{ Inactive } \\
\hline 7-Dehydrocholesterol & Coprostanol \\
\hline Desmosterol & Cholestane \\
\hline Lanosterol & Squalene \\
\hline 24-Dihydrolanosterol & Calciferol \\
\hline Cycloartenol & DL- $\alpha$-Tocopherol \\
\hline Ergosterol peroxide & Diosgenin \\
\hline$\Delta^{5}$-Cholenic acid & Tomatidine \\
\hline Bisnorcholenic acid & Solanidine \\
\hline$\Delta^{5}$-Pregnenol & Coumarin \\
\hline$\Delta^{5}$ - Pregnen-3 $\beta$-ol-20-one & Polyporenic acid A \\
\hline Progesterone & Lecithin \\
\hline Testosterone & Oleic acid \\
\hline Dehydroepiandrosterone & Sodium acetate \\
\hline Oestrone & \\
\hline
\end{tabular}

The various active compounds were compared in a series of tests in which the sterols were added at $10 \mathrm{mg}$./ $\mathrm{l}$. The relative activities were assessed by three criteria: (1) by the time of appearance of oogonia and oospores; (2) by the relative numbers of oospores; (3) by the effect on linear growth rate. The data for the first of these criteria are the most complete and Figs. 3-6 show the proportion of plates in which oogonia and oospores were seen on successive days. On this basis the greatest activity was shown by isofucosterol and $\beta$-sitosterol. Cholesterol promoted slightly less rapid development, while ergosterol and stigmasteryl acetate were somewhat slower. Development with $\Delta^{\mathbf{7}}$-cholestenol was very slow.

The time of appearance of sexual organs in the culture was related to the linear growth of the hyphae. Generally reproductive bodies did not appear until after the 
hyphae had reached the edge of the Petri dish. The most rapid growth was promoted by $\beta$-sitosterol and cholesterol among substances tested in this way (Table 2); oogonia and oospores appeared sooner with these substances than with ergosterol, with which hyphal growth was slower.

As regards the number of oospores produced in a culture (Tables 3-4), isofucosterol and $\beta$-sitosterol were easily the most active, but considerable numbers were also produced with cholesterol. Stigmasteryl acetate and ergosterol were less active and few oospores were found with fucosterol and $\Delta^{7}$-cholestenol.

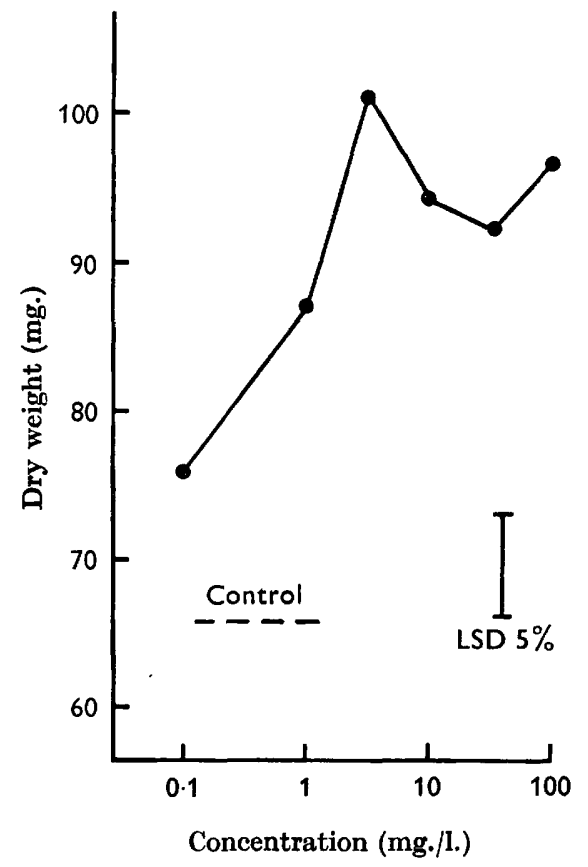

Eig. 1

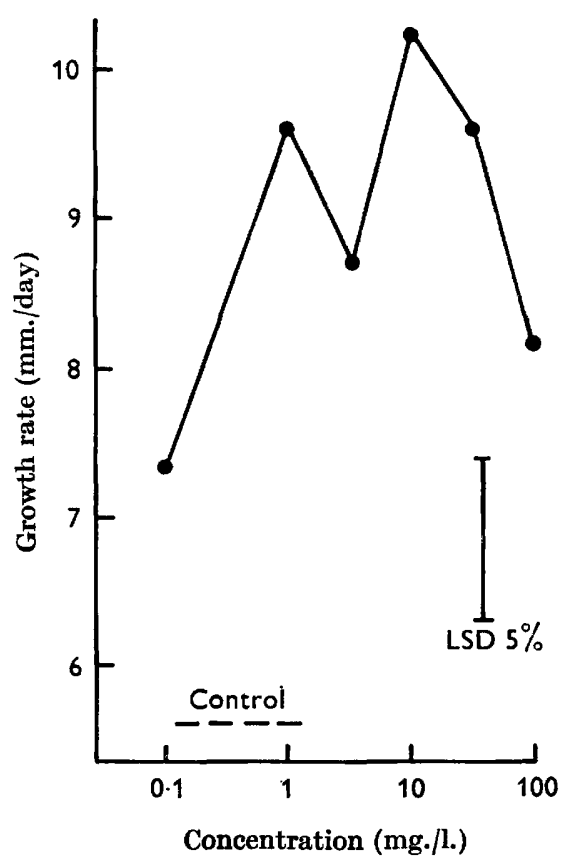

Fig. 2

Fig. 1. Effect of concentration of $\beta$-sitosterol on growth (dry weight) of Phytophora cactorum. Mycelium harvested after 18 days incubation at $25^{\circ}$.

Fig. 2. Effect of concentration of $\beta$-sitosterol on linear growth rate of hyphae of Phytophthora cactorum. Scale refers to $\mathrm{mm}$. increase per day in colony diameter.

With fucosterol at $10 \mathrm{mg} . /$ l. oogonia appear early (Fig. 4) and in great numbers, but oospores were slow to appear, not being seen until 4 days later, and then only a very small proportion (about $1 \%$ ) of the oogonia formed them. However, the oospore count was considerably increased at fucosterol $100 \mathrm{mg}$./l. (Table 4, Expt. 5).

A few oogonia but no oospores were formed with $\beta$-sitosterol at $0.1 \mathrm{mg}$./l. and with fucosterol at $1 \mathrm{mg} . / \mathrm{l}$.

There was great variation from one experiment to another. This was especially true with the growth rate on basal medium, less so on cholesterol medium (Table 2). These differences might have been due in part to differences in the way the medium was made, but were largely due to variation in the fungus. In some experiments a fast-growing strain was used, in others a slow one (Table 2, Expt. 3); these arose 

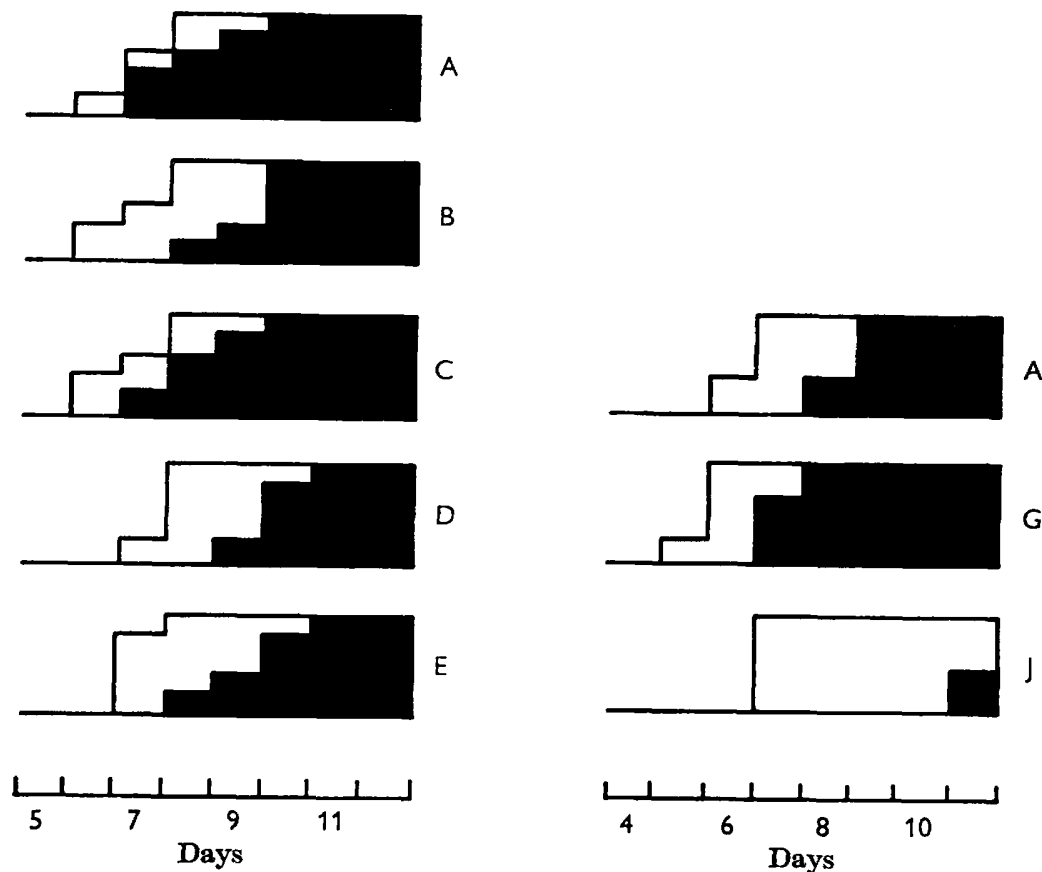

Fig. 3

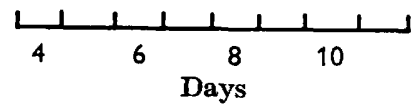

Fig. 4
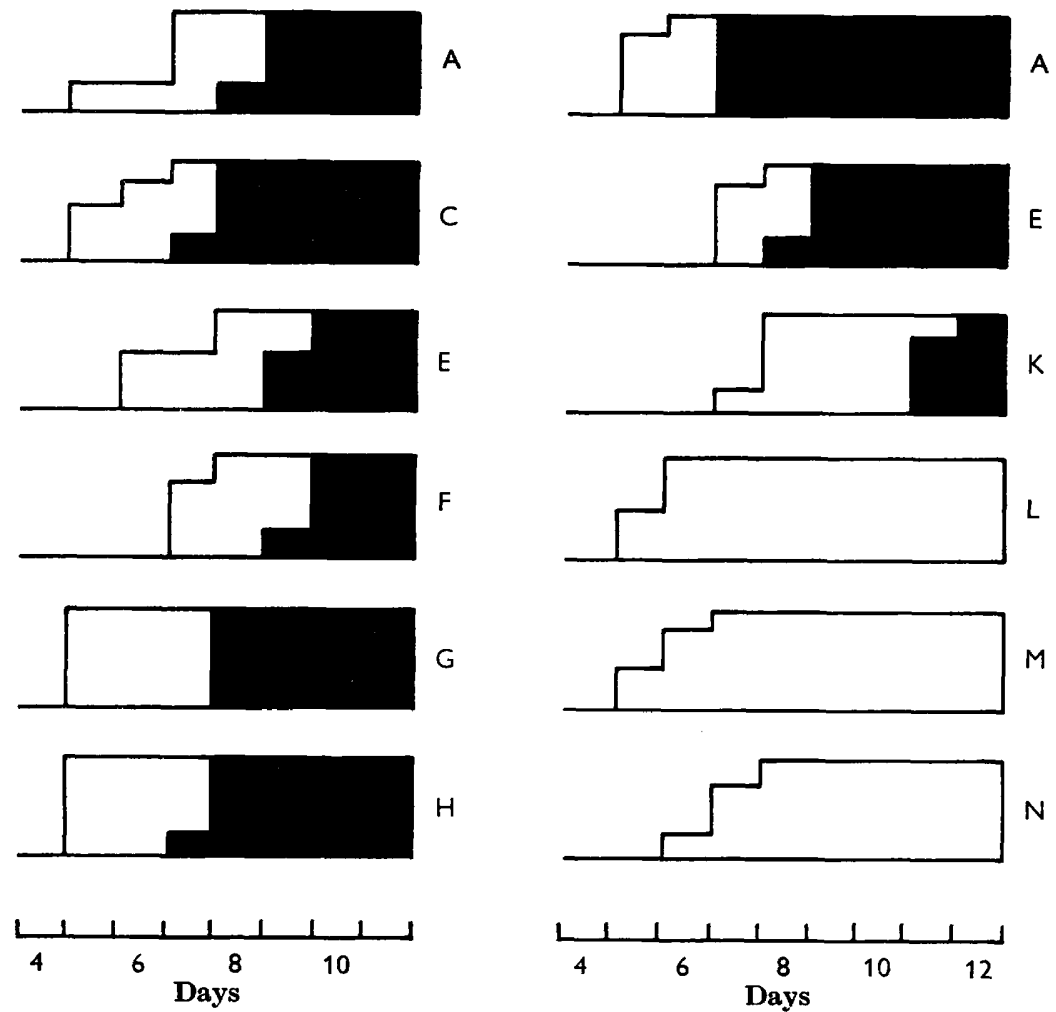

Fig. 5

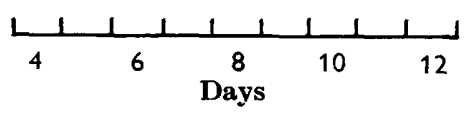

Fig. 6

Figs. 3-6. Phytophthora cactorum: course of development of sexual organs in variously supplemented media in four experiments. The vertical axis represents the proportion of cultures having oogonia (white) and oospores (black) on successive days.

A, Cholesterol; B, cholesteryl acetate; C, $\beta$-sitosterol; D, stigmasteryl acetate; E, ergosterol, sample 1 ; F, ergosterol, sample 2 ; $G$, isofucosterol, sample 1 ; $\mathbf{H}$, isofucosterol, sample 2; J, fucosterol; K, $\Delta^{7}$-cholestenol; $\mathbf{M}, \Delta^{5}$-cholenol; N, $\Delta^{5}$-cholesten3-one. 
Table 2. Phytophthora cactorum: growth rates ( $\mathrm{mm}$. increase in diameter of colony/day) in $9 \mathrm{~cm}$. Petri dishes in basal medium with sterols added at $10 \mathrm{mg} . / \mathrm{l}$.

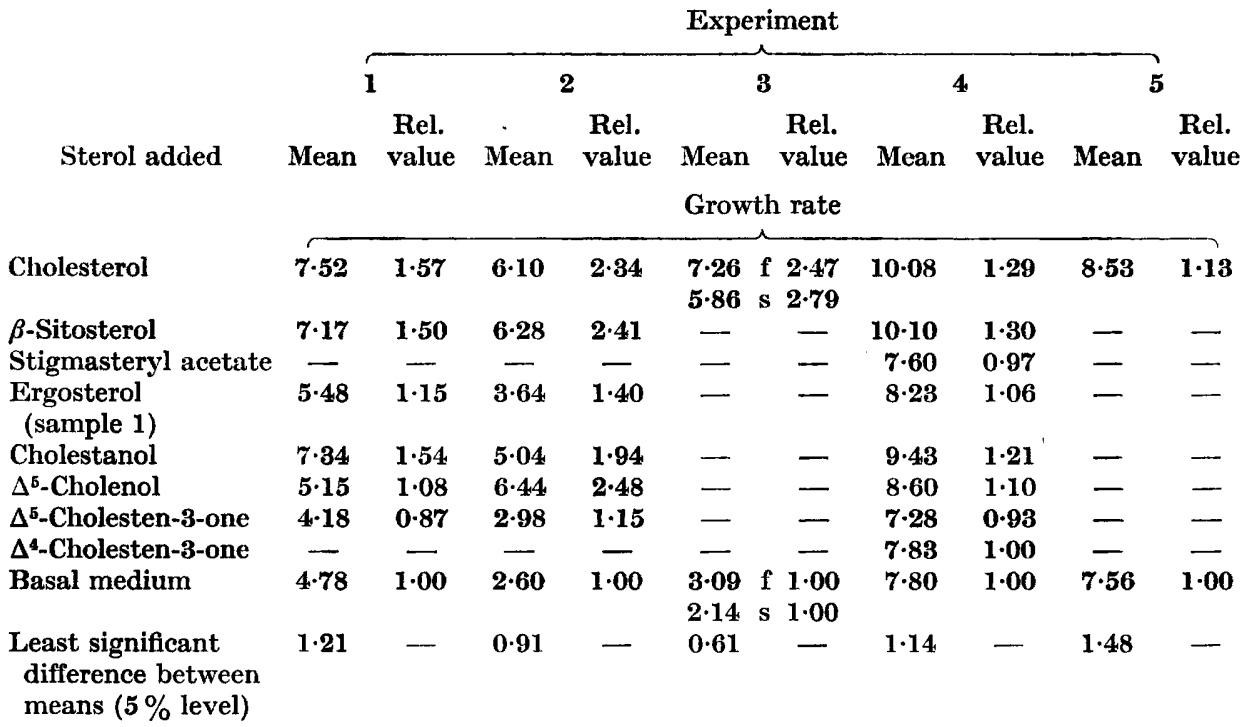

In Expt. 3, f and s were fast-growing and slow-growing segregants from one colony.

Table 3. Phytophthora cactorum: oospore counts in relation to activity of sterols

Counts were made in three radial transects in each of 5 dishes (day 1) and again in the same dishes one week later (day 2). Sterol concentration $=10 \mathrm{mg} . / 1$. in all cases.

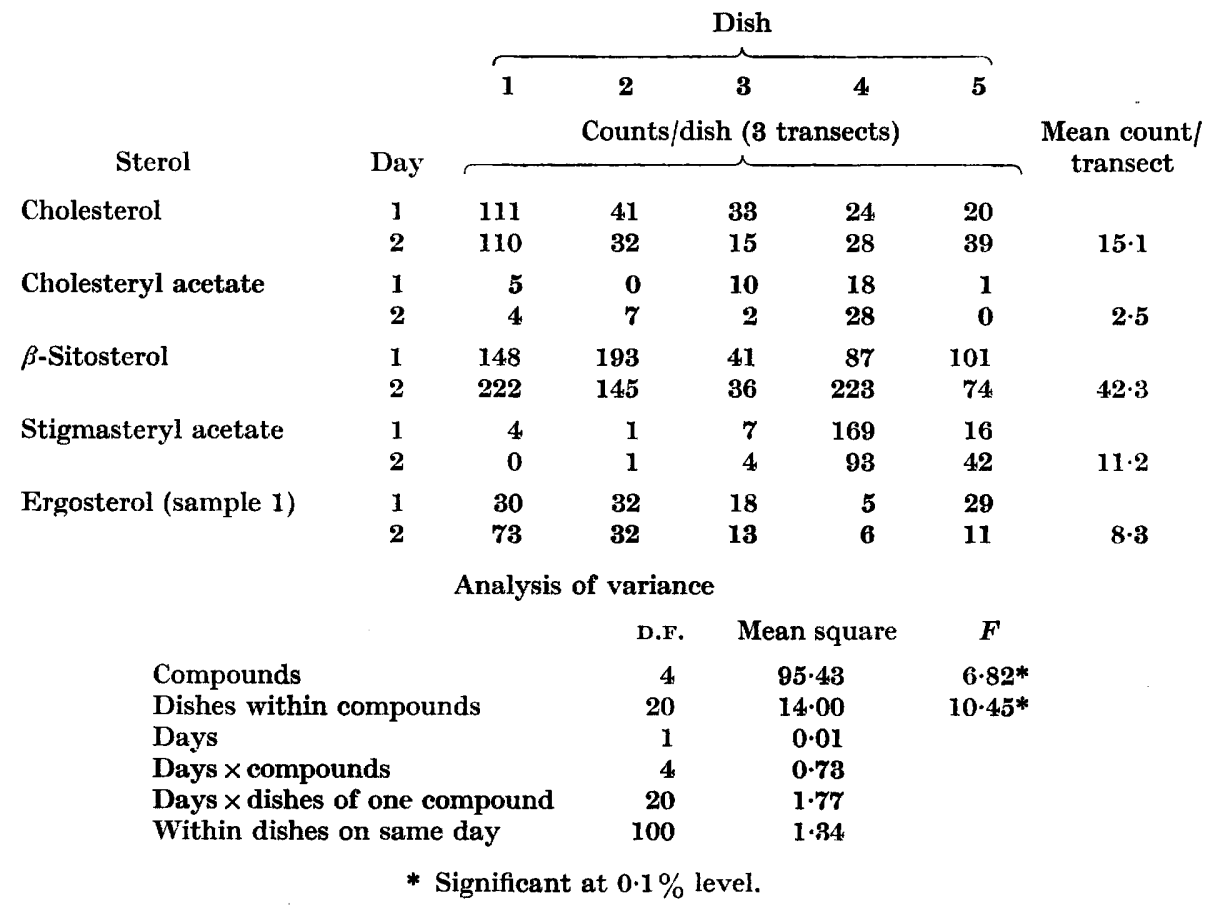


by segregation from the original strain. Again, in different experiments with cholesterol medium, oogonia appeared in 4 to 8 days. There were also considerable differences in the number of oospores produced in different experiments (Table 4). Nevertheless, a similar pattern was seen in each experiment when we compared the activities of different sterols relative to the standards, basal medium and cholesterol.

$\beta$-Sitosterol and isofucosterol are the principal sterols present in oats (Knights, 1965). Since these are the most active substances tested it is evident why oatmeal agar has always been found to be a most satisfactory natural medium for sexual stages of the phytophthora species.

Table 4. Phytophthora cactorum: oospore counts as affected by sterols in five experiments

\begin{tabular}{|c|c|c|c|c|c|c|}
\hline \multirow{2}{*}{ Sterol } & \multirow[b]{2}{*}{$\begin{array}{l}\text { Concen- } \\
\text { tration } \\
\text { (mig./l.) }\end{array}$} & \multicolumn{5}{|c|}{ Experiment } \\
\hline & & $1 *$ & $\begin{array}{l}2 \\
\mathrm{Me}\end{array}$ & $\begin{array}{c}3 \\
\text { ount } /\end{array}$ & $\begin{array}{r}4 \\
\text { nsect }\end{array}$ & 5 \\
\hline Cholesterol & 10 & $15 \cdot 1$ & $5 \cdot 4$ & $\mathbf{2} \cdot \mathbf{0}$ & 一 & - \\
\hline Cholesteryl acetate & 10 & $\mathbf{2} \cdot \mathbf{5}$ & - & - & - & 一 \\
\hline$\beta$-Sitosterol & $\begin{array}{c}100 \\
10 \\
1 \\
0 \cdot 1\end{array}$ & $\begin{array}{r}- \\
42 \cdot 3 \\
- \\
-\end{array}$ & $\begin{array}{l}- \\
- \\
-\end{array}$ & $\begin{array}{r}- \\
22 \cdot 0 \\
- \\
-\end{array}$ & $\begin{array}{c}120 \cdot 2 \\
126 \cdot 0 \\
17 \cdot 8 \\
0\end{array}$ & $\begin{array}{c}-\overline{68 \cdot 0} \\
1 \cdot 7 \\
0\end{array}$ \\
\hline Isofucosterol, sample 1 & 10 & 一 & $52 \cdot 6$ & $8 \cdot 1$ & - & - \\
\hline Fucosterol & $\begin{array}{r}100 \\
10 \\
1\end{array}$ & - & - & - & - & $\begin{array}{l}5 \cdot 6 \\
1 \cdot 0 \\
0\end{array}$ \\
\hline $\begin{array}{r}\text { Ergosterol, sample } 1 \\
\text { sample } 2\end{array}$ & $\begin{array}{l}10 \\
10\end{array}$ & $\underline{8 \cdot 3}$ & $\begin{array}{l}8 \cdot 2 \\
-\end{array}$ & $\overline{0 \cdot 2}$ & - & - \\
\hline Stigmasteryl acetate & 10 & $11 \cdot 2$ & 一 & - & - & - \\
\hline
\end{tabular}

\section{Partially active substances}

The substances found to be partially active are listed in the second part of Table 1.

When cholestanol was added to the medium at 2.5, 10, 40 and $160 \mathrm{mg} . / 1$. , oogonia developed at all concentrations, but no oospores were seen. With $\Delta^{5}$-cholesten-3-one and $\Delta^{4,6}$-cholestadien-3-one, oogonia but no oospores were produced when the substances were added at 1,10 , and $100 \mathrm{mg}$./1. In these cases, increasing the concentration of the substance did not lead to oospore production. The distinction between active and partially active substances would thus appear to be a real qualitative one.

The addition of cholestanol and $\Delta^{5}$-cholenol to the medium resulted in the production of oogonia early, generally at the same time as with cholesterol (Fig. 6). These substances significantly increased the hyphal growth rate (Table 2 ). With the three cholestenones, the oogonia appeared later, about 2 days after the cholesterol controls. These compounds did not increase hyphal growth as much as did cholestanol and $\Delta^{5}$-cholenol. 


\section{Inactive substances}

Substances found to be inactive are shown in the third part of Table 1. Inactive substances were not always without morphogenetic effects. Irregular swelling of the hyphae was observed especially with 7-dehydrocholesterol and ergosterol peroxide, and with coprostanol many curiously coiled and twisted hyphae appeared where one would expect oogonia and antheridia. Lecithin and oleic acid were both inactive, although oleic acid has been found to stimulate vegetative growth (Hendrix, 1965). However, the addition of lecithin or oleic acid to medium with cholesterol at $10 \mathrm{mg}$./l. increased the numbers of oospores (see Table 5) although the scale of the experiments was inadequate to give a significant result in the case of oleic acid. Oleic acid and lecithin enhance the activity of cholesterol in the sterol-requiring protozoan Tetrahymena corlissi (Holz et al. 1961).

Table 5. Phytophthora cactorum: effect of lecithin and oleic acid on oospore production in medium containing cholesterol $10 \mathrm{mg} . / \mathrm{l}$.

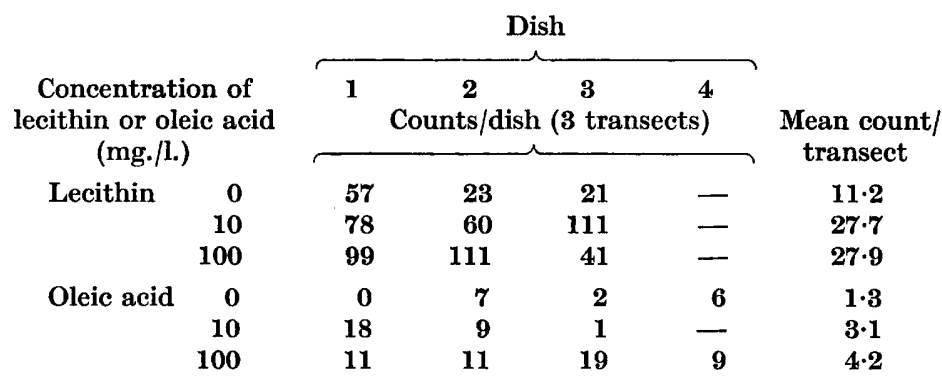

Analysis of variance

\begin{tabular}{|c|c|c|c|}
\hline \multicolumn{2}{|r|}{ Lecithin } & \multicolumn{2}{|c|}{ Oleic acid } \\
\hline D.F. & Mean square & D.F. & Mean square \\
\hline 1 & $22 \cdot 338+$ & 1 & $3 \cdot 228 *$ \\
\hline $\mathbf{1}$ & 0.018 & 1 & 1.033 \\
\hline 6 & $3 \cdot 434$ & 8 & 0.838 \\
\hline 18 & $1 \cdot 114$ & 22 & 0.470 \\
\hline
\end{tabular}

Between concentrations

Presence vs. absence

100 vs. $10 \mathrm{mg} . / \mathrm{l}$.

Between dishes at one concentration

Between transects in one dish

* Significant at $5 \%$ level compared with counts in one dish, not significantly greater than difference between dishes.

+ Significant at $0 \cdot 1 \%$ level compared with counts in one dish, and at $5 \%$ level compared with differences between dishes.

\section{An effect of agar}

We previously reported the occurrence of oospores in small numbers in cultures grown on basal medium, and with some substances now classified as inactive and partially active (Elliott et al. 1964). This was due to the use at that time of Oxoid agar No. 3. Subsequently we used only Difco Bacto-Agar and, with this, no oospores were formed on the basal medium, although in some of the tests a few oogonia appeared at a late stage of growth. With partially active substances, the use of Oxoid agar sometimes resulted in the early appearance of oospores, whereas with the Difco agar the oogonia appeared early but were not followed by oospores. It would appear that some factor in Difco agar is limiting and this emphasizes the differences in activity between various steroids in promoting sexual reproduction. 


\section{DISCUSSION}

A comparison of the molecular structures of the active compound, cholesterol Fig. 7, II) with the partially active ones, $\Delta^{5}$-cholesten-3-one (VI), cholestanol (V), and $\Delta^{5}$-cholenol (III), each of which differs from cholesterol in one point only, shows

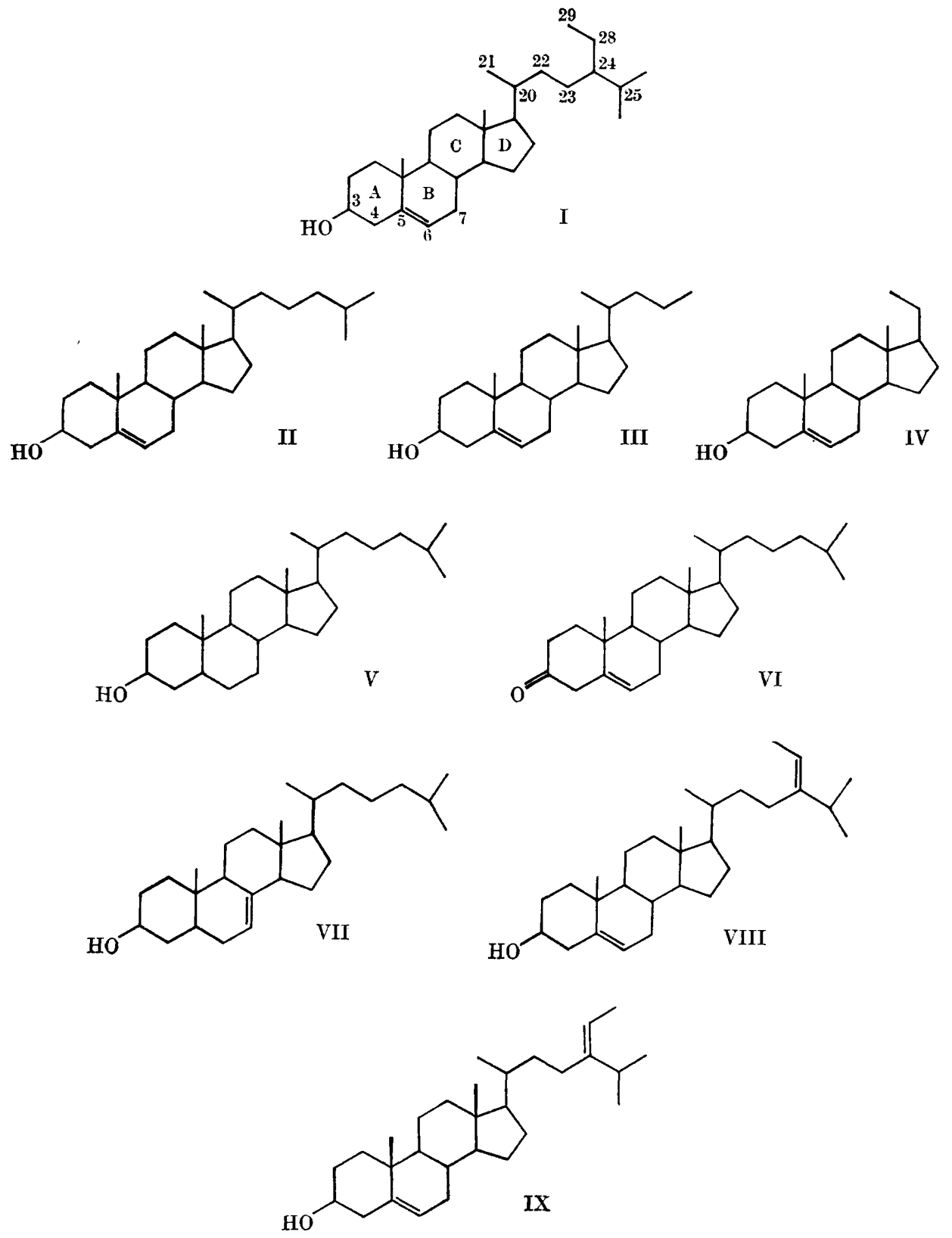

Fig. 7. Structures of sterols tested: I, $\beta$-sitosterol; II, cholesterol; III, $\Delta^{5}$-cholenol; IV, $\Delta^{5}$-pregnenol; V, cholestanol; VI, $\Delta^{5}$-cholesten-3-one; VII, $\Delta^{7}$-cholestenol; VIII, 29isofucosterol; IX, fucosterol. 


\section{4}

C. G. Elifiott, M. R. Hendrie and B. A. Knights

that to induce sexual activity and allow its completion in Phytophthora cactorum the sterol nucleus is required with a hydroxyl group at carbon 3 , a double bond in the $B$ ring, and a side chain of more than five carbon atoms.

Only compounds with a hydrocarbon side chain are active. For example, while cholenol has some partial activity, cholenic acid (Fig. 8, XV) has none, and such<smiles>[X]C=C1C=CC2CC(O)CCC12CCCC12CCC(C(C)/C=C/C(C)C(C)C)C1CC2</smiles>

$\mathrm{X}$<smiles>CCCCCC(C)C1CCC2C3=CC=C4CC(O)CCC4(C)C3CCC21C</smiles>

XI<smiles>CC(C)=CCCC(C)C1CCC2C3CC=C4CC(O)CCC4(C)C3CCC12C</smiles><smiles>CC(CCC(=O)O)C1CCC2C3CC=C4CC(O)CCC4(C)C3CCC12C</smiles>

Fig. 8. Structures of sterols tested: X, ergosterol; XI, 7-dehydrocholesterol; XII, stigmasteryl acetate $\left(\mathrm{Ac}=\mathrm{CH}_{3} . \mathrm{CO}-\right)$; XIII, desmosterol; $\mathrm{XIV}$, diosgenin; $\mathrm{XV}$, cholenic acid.

substances as diosgenin (XIV) and solanidine with their much modified side chains are also inactive. The mammalian sex hormones with their short and modified side chains are inactive. Increasing the length of the side chain results in increasing activity, as shown by the series pregnenol (IV), cholenol (III), cholesterol (II), $\beta$-sitosterol (I).

One of the most striking results obtained relates to the position of the 29th carbon atom. The double bond linking carbons 24 and 28 holds no. 29 in one position in 29-iso-fucosterol (VIII) and in the alternative position in fucosterol (IX). The first of these is perhaps the most active substance found; with the second few oospores were formed although oogonia were very numerous. In $\beta$-sitosterol, the 29 th carbon is free to rotate; it could presumably readily adopt the isofucosterol configuration in fitting into some cellular structure. 
A double bond in the side chain at carbon 22 results in slower development, stigmasteryl acetate (Fig. 8, XII) being less active than $\beta$-sitosteryl acetate. A double bond at carbon 24 as in desmosterol (XIII), however, surprisingly results in no activity. Ergosterol (X) has a double bond at carbon 22, but it also has an extra methyl group at carbon 24 and this would increase the resemblance of the side chain to that of $\beta$-sitosterol.

7-Dehydrocholesterol (XI) was inactive. It has two double bonds in the B ring. Ergosterol has the same B ring structure, and its activity (in contrast to the inactivity of 7-dehydrocholesterol) is presumably due to a compensatory effect of its side chain configuration.

7-Dehydrocholesterol, $\Delta^{7}$-cholestenol and ergosterol all support the growth of Tetrahymena corlissi (Holz et al. 1961) and overcome the inhibition of growth of T. pyriformis induced by triparanol (Holz, Erwin, Rosenbaum \& Aaronson, 1962). However, only the first two support the growth of the beetle Dermestes vulpinus (Clayton \& Bloch, 1963). On the other hand (and as we find in Phytophthora cactorum) ergosterol is active but 7-dehydrocholesterol inactive in promoting growth of a parasitic mycoplasma (Smith \& Lynn, 1958). Ergosterol is slightly active in inducing oospore formation in a pythium s.o. (Haskins et al. 1964).

The partially active compounds, which allowed the appearance of oogonia and antheridia but not the consummation of the sexual process, are interesting. A knowledge of why the course of development breaks down with them would go far towards explaining the regulation of sexual processes by sterols in these fungi.

This work was supported by a grant from the Department of Scientific and Industrial Research.

\section{REFERENCES}

Clayton, R. B. \& Bloch, K. (1963). Sterol utilization in the hide beetle, Dermestes vulpinus. J. biol. Chem. $238,586$.

Elliott, C. G., Hendrie, M. R., Knights, B. A. \& PARker, W. (1964). A steroid growth factor requirement in a fungus. Nature, Lond. 203, 427.

HARnish, W. N., Berg, L. A. \& Lilly, V. G. (1964). Factors in lima bean and hemp seed required for oospore formation by species of Phytophthora. Phytopathology, 54, 895.

Haskins, R. H., Tulloch, A. P. \& Mrcerich, R. G. (1964). Steroids and the stimulation of sexual reproduction of a species of Pythium. Canad. J. Microbiol. 10, 187.

HeNDrIx, J. W. (1964). Sterol induction of reproduction and stimulation of growth of Pythium and Phytophthora. Science, 144, 1028.

HENDRIX, J. W. (1965). Influence of sterols on growth and reproduction of Pythium and Phytophthora spp. Phytopathology, 55, 790.

Holz, G. G., Erwin, J., Rosenbaum, N. \& Aaronson, S. (1962). Triparanol inhibition of Tetrahymena, and its prevention by lipids. Arch. Biochem. Biophys. 98, 312.

Holz, G. G., W AGner, G., Erwin, J., BritT, J. J. \& Bloch, K. (1961). Sterol requirements of a ciliate, Tetrahymena corlissi Th-X. Comp. Biochem. Physiol. 2, 202.

KNights, B. A. (1965). Identification of the sterols of oat seed. Phytochemistry 4, 857.

Leal, J. A., Friend, J. \& Holliday, P. (1964). A factor controlling sexual reproduction in Phytophthora. Nature, Lond. 203, 545.

Smith, P. F. \& LYNN, R. J. (1958). Lipid requirements for the growth of pleuropneumonialike organisms. J. Bact. 76, 264. 